\title{
ANALISIS PENGARUH MOMENT GYROSCOPE PADA KESEIMBANGAN PENDULUM CARTESSIAN
}

\author{
M. I. Nugraha ${ }^{1}$, J. Hartati ${ }^{2}$, W. Afridani ${ }^{3}$, Masdani ${ }^{4}$ \\ 1,2,3 Jurusan Teknik Elektro dan Informatika, Politeknik Manufaktur Negeri Bangka Belitung \\ Sungailiat, Bangka Belitung, Indonesia, 33211 \\ ${ }^{4} J u r u s a n$ Teknik Mesin - Politeknik Manufaktur Negeri Bangka Belitung \\ Kawasan Industri Air Kantung, Sungailiat-Bangka, 33211 \\ Tel: 0717-93586, Fax: 0717-93585, iqbal@polman-babel.ac.id
}

\begin{abstract}
Crane is identical to the pendulum in term of its control mechanism. Based on modelling, these two devices are very similar and therefore, the pendulum can be used as a prototype for controlling a crane. This research aims to control the balance or to reduce the swing on the pendulum by utilizing the moment of gyroscope with a mass pendulum up to $1.5 \mathrm{~kg}$. Gyroscope was designed and made in the form of a disc, in which dimensions and materials used were determined according to the desired moment force. The PID controller was used to control the speed of gyroscope based on the angle of the

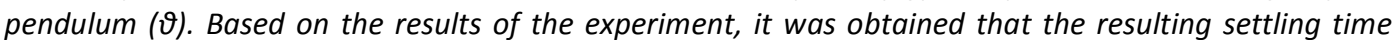
was 2.29 times faster than without control in average. The overshoot and rise time resulted by the system using gyroscope were very similar to the system which is without gyroscope. However, the steady state error was totally eliminated. It can be concluded that the moment of gyroscope is able to be used for controlling the pendulum or crane.
\end{abstract}

Keywords: crane, pendulum, moment, gyroscope, PID

\begin{abstract}
Abstrak
Alat berat berupa crane memiliki karakteristik yang identik dengan pendulum dalam mekanisme pengontrolannya. Artinya secara model matematik, kedua perangkat ini sangat mirip dan oleh sebab itu, pendulum bisa dijadikan prototipe untuk pengontrolan sebuah crane. Penelitian ini bertujuan untuk mengontrol keseimbangan atau meredam ayunan pada pendulum dengan memanfaatkan gaya momen pada gyroscope dengan massa pendulum hingga $1,5 \mathrm{~kg}$. Gyroscope dirancang dan dibuat dalam bentuk piringan, yang mana dimensi dan material yang digunakan dihitung berdasarkan gaya momen yang diinginkan. Kontroler PID digunakan untuk mengendalikan kecepatan putaran gyroscope berdasarkan sudut kemiringan pendulum $(\theta)$. Berdasarkan hasil uji coba, diperoleh settling time yang dihasilkan adalah rata-rata 2,29 kali lebih cepat dibandingkan tanpa kontrol. Untuk overshoot dan rise time tidak banyak berubah, sedangkan steady state error adalah nol. Dapat disimpulkan bahwa moment gyroscope bisa digunakan untuk mengontrol pendulum dan sangat memungkinkan dalam pengendalian crane.
\end{abstract}

Kata kunci : crane, pendulum, moment, gyroscope, PID

\section{PENDAHULUAN}

Perangkat pendulum dalam kehidupan nyata dapat dilihat dalam aplikasi berupa alat berat pemindah barang atau sering disebut juga dengan crane. Alat berat berupa crane memiliki karakteristik yang identik dengan pendulum dalam mekanisme pengontrolannya. Dalam praktiknya, crane digunakan secara luas untuk berbagai lapangan pekerjaan, seperti di pelabuhan, pabrik, kontruksi dan lainnya untuk menangani barang-barang[1]. Secara matematik, gyroscope dapat dimodelkan berdasarkan hukum energi kinetik dan perubahan momentum sudut[2]. Dalam beberapa kurun waktu, pendulum dapat menjalani berbagai perubahan di negara bagian, termasuk pada saat penelitian[3]. Teknik kontrol pendulum yang dilakukan selama ini, selalu mengasumsikan bahwa aktuator yang digunakan bisa mendukung untuk dilakukan pergerakan yang cepat dan akurat. Namun, dalam kenyataannya, aktuator yang digunakan pada crane tidak bisa digunakan untuk pergerakan yang cepat. Oleh karena itu, sistem kontrol yang handal tidak akan mampu diterapkan secara real ke sistem kontrol crane, jika tingkat 
mobilitas dan fleksibilitas aktuator pada plant tersebut rendah. Berdasarkan permasalahan yang ada, penelitian ini mencoba merancang suatu alternatif baru dalam teknik pengontrolan alat yang bertipe pendulum dengan melibatkan atau memanfaatkan fenomena gaya momen pada gyroscope. Gyroscope yang dimaksud disini adalah aktuator tambahan yang digunakan sebagai media yang akan menghasilkan gaya yang berlawanan untuk meredam getaran atau ayunan pada objek atau barang yang akan dipindahkan. Ketika sebuah gyroscope diputar dengan kecepatan tertentu, maka ada gaya reaksi yang terjadi dengan arah tegak lurus terhadap arah putaran tersebut.

\section{METODE PENELITIAN}

\subsection{Sistem Kontrol Pendulum}

Teknik sistem kontrol pendulum pada dasarnya bertujuan untuk memperpendek settling time, mereduksi overshoot dan mengeliminasi steady state error pada saat signal aktuasi diberikan ke pendulum. Untuk mencapai ini, teknik sistem kontrol berbasis PID controller bisa diterapkan dengan metode tuning yang baik [4]. Dengan mendapatkan konstanta yang sesuai pada masing-masing variabel kontroler, hasil yang diinginkan pada pengontrolan pendulum bisa dicapai. Sebuah pendulum ( bandul ) dianggap sebagai gerak berayun bebas dan periodik berdasarkan gesekan sebagai respon dari gaya gravitasi. Jika beban ditarik dari posisi seimbang dengan sudut simpangan tidak lebih dari 10 , kemudian dilepaskan maka beban akan berayun pada bidang vertikal [5]. Sebuah sistem bandul matematik atau bandul sederhana terdiri atas sebuah benda bermassa $m$ yang dimensinya kecil, sehingga dapat dianggap sebagai partikel berupa titik, digantungkan pada seutas tali membentuk ayunan seperti pada gambar 2.1.

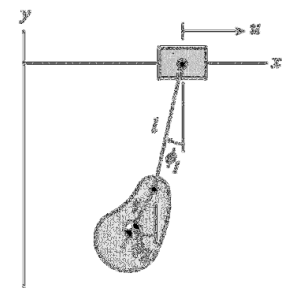

Gambar 2.1 Model Sistem Pendulum [6]

\subsection{Gyroscope}

Gyroscope adalah sebuah perangkat yang terdiri dari sebuah piringan atau roda yang bisa diputar dengan cepat pada suatu axis tertentu secara bebas [7]. Dengan adanya putaran tersebut, maka ada perubahan momen gaya yang ditimbulkan secara tegak lurus dengan arah putaran. Dalam dunia instrumentasi, gyroscope digunakan untuk mengukur orientasi berdasarkan prinsip momentum sudut. Sensor ini akan mengukur kecepatan sudut dari suatu rotasi yang satuannya adalah radian per detik. Mekanismenya adalah sebuah roda berputar dengan piringan didalamnya yang tetap stabil. Secara matematik, gyroscope dapat dimodelkan berdasarkan hukum energi kinetik dan perubahan momentum sudut [2].

Dengan pemodelan, reaksi dari pergerakan gyroscope bisa diobservasi. Efek gaya yang ditimbulkan pada sebuah gyroscope bisa dilihat pada gambar 2.2.

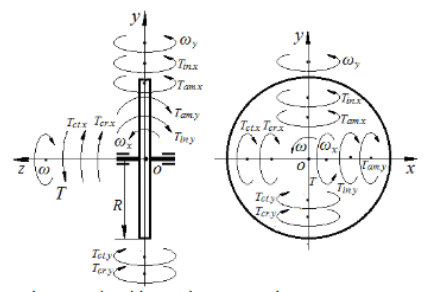

Gambar 2.2 Torsi dan Gaya Internal Gyroscope [2]

Gaya inersia yang ditimbulkan oleh gyroscope dimanfaatkan untuk memberikan reaksi pada sistem keseimbangan. Pada kecepatan yang tinggi lalu secara mendadak dilakukan pengereman, maka 
gaya inersia yang ditimbulkan cukup untuk menggerakkan sebuah massa tertentu. Kecepatan putaran gyroscope menentukan besarnya gaya inersia yang dihasilkan, disamping massa dan diameter[8].

\section{HASIL DAN PEMBAHASAN}

\subsection{Konstruksi Prototipe Crane}

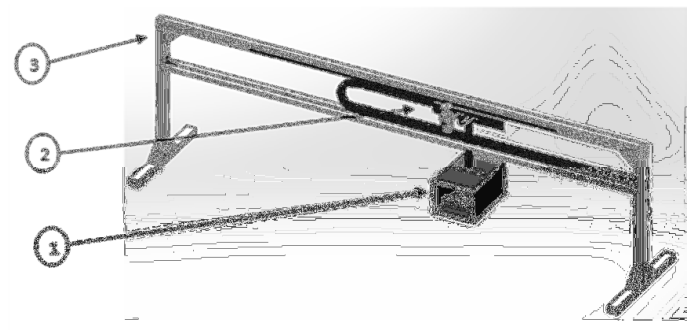

Gambar 3.1 Prototype Konstruksi Pendulum

Pada gambar 3.1 bagian-bagian konstruksi prototipe crane yang dibangun diantaranya adalah (1) box pendulum, di dalamnya sudah terpasang dengan gyroscope; (2) pembawa cartessian; dan (3) konstruksi rangka crane cartessian.

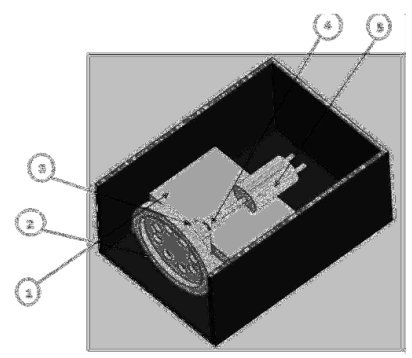

Gambar 3.2 Perangkat di dalam Box Pendulum

Perangkat yang terdapat pada box pendulum seperti yang terlihat pada gambar 3.2 meliputi: (1) Dudukan gyroscope; (2) Piringan gyroscope; (3) Hose bearing; (4) Coupler / penghubung poros; dan (5) Motor DC.

Konstruksi prototipe crane ini dilengkapi kerangka kontruksi berukuran $50 \mathrm{~cm}$ dan panjang 180 $\mathrm{cm}$ dengan jangkauan pergerakan bandul mencapai $150 \mathrm{~cm}$. Massa box pendulum bisa ditambah dengan beban hingga 1,5 kg. Box pendulum menggantung pada rangka prototipe crane melalui sebuah pelat penyangga. Pelat penyangga tersebut terhubung dengan sebuah motor DC yang dapat begerak pada rell sliding sepanjang rangka prototipe crane. Pada bagian ujung rell sliding diletakkan sebuah limit switch (saklar pembatas) yang berfungsi sebagai sensor pembatas pergerakan pendulum. Pada bagian protipe ini juga terdapat komponen hardware berupa sensor sudut yang dipasang pada poros putar pendulum. Sensor sudut digunakan untuk membaca sudut kemiringan atau posisi ayunan pendulum.

\subsection{Rancangan Sistem}

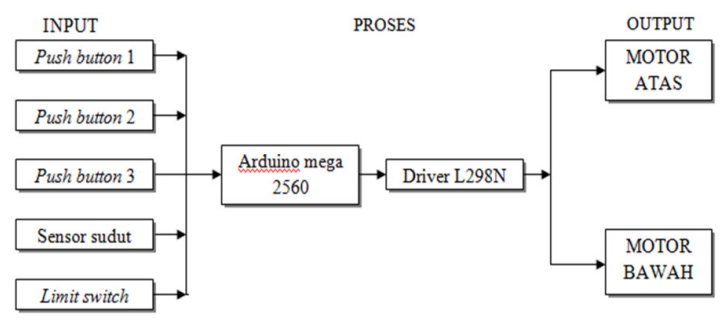

Gambar 3.3 Blok Diagram Hardware Elektrikal Pendulum 


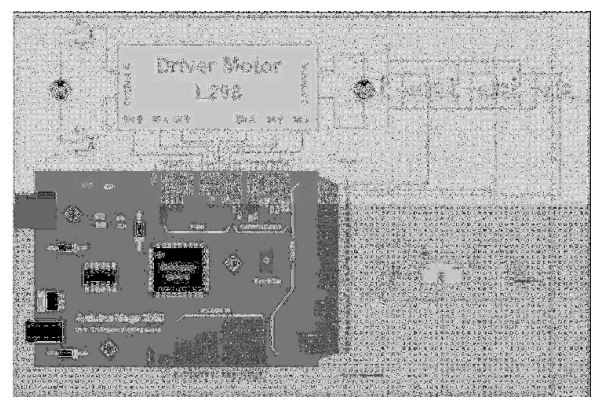

Gambar 3.4 Skematik Rangkaian Elektronika

Pada gambar 3.3 terlihat bahwa penelitian ini menggunakan dua buah motor DC, yakni motor atas (pembawa crane) dan motor bawah (penggerak gyroscope). Secara skematik, rangkaian elektronika dari sistem kontrol alat ini dapat dilihat pada gambar 3.4.

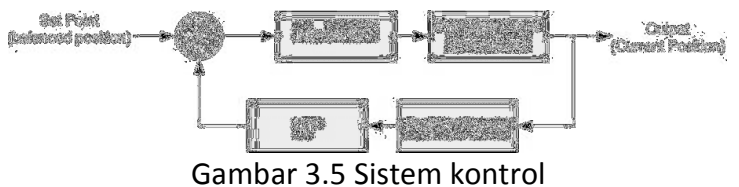

Motor pembawa crane dikontrol melalui tombol yang biasanya dioperasikan oleh para operator crane di industri. Dari sini, tidak ada yang berbeda dengan sistem kerja crane pada umumnya. Yang membedakannya adalah bahwa motor penggerak gyroscope akan aktif ketika sudut kemiringan pendulum tidak sama dengan nol, atau pendulum tersebut berayun. Set pointnya adalah posisi bandul harus selalu tegak lurus ketika operator menggerakkan motor pembawa crane.

Pada gambar 3.5 tampak sistem kontrol yang digunakan pada penelitian ini. Sistem kontrol PID digunakan untuk mengontrol kecepatan putaran gyroscope sebagai representasi gaya redaman ayunan. Sebuah Low Pass Filter (LPF) digunakan untuk mengeliminasi efek noise yang ditimbulkan oleh sensor saat pembacaan posisi pendulum. Untuk cutoff frequecny $\left(\omega_{c}\right)$ sebesar $30 \mathrm{rad} / \mathrm{s}$ sudah cukup untuk menghilangkan noise yang muncul dari sensor.

\subsection{Hasil Percobaan}

\subsubsection{Hasil Percobaan Pendulum Tanpa Gyroscope dan Dengan Gyroscope}

Uji coba bertujuan untuk membandingkan berapa lama waktu yang diperlukan untuk meredam ayunan (settling time) tanpa gyroscope dan dengan menggunakan gyroscope. Adapun hasil uji coba dapat dilihat pada table 3.1 berikut.

Tabel 3.1 Hasil percobaan pendulum tanpa gyroscope dan dengan gyroscope

\begin{tabular}{|c|c|c|c|c|}
\hline \multirow{4}{*}{$\begin{array}{l}\text { Sudut } \\
\text { Igan }\end{array}$} & \multicolumn{4}{|c|}{ Waktu (s) } \\
\hline & \multicolumn{2}{|c|}{ Tanpa Gyroscope } & \multicolumn{2}{|c|}{ Dengan Gyrsocope } \\
\hline & $\mathrm{Kd}=5$ & $\mathrm{Kd}=5$ & $\mathrm{Kd}=5$ & $\mathrm{Kd}=5$ \\
\hline & $K p=5$ & $K p=20$ & $K p=5$ & $K_{p}=20$ \\
\hline $60^{\circ}$ & 45 & 38 & 36 & 29 \\
\hline $45^{\circ}$ & 31 & 28 & 221 & 19 \\
\hline $30^{\circ}$ & 18 & 16 & 12 & 8 \\
\hline $0^{0}$ & 0 & 0 & 0 & 0 \\
\hline
\end{tabular}

Berdasarkan tabel 3.1, dapat dilihat bahwa besarnya sudut kemiringan menentukan lamanya pendulum tersebut akan mencapai kondisi stabil setelah berayun. Percobaan yang dilakukan adalah sebanyak empat kali, dimana dua kali tanpa kontrol gyroscope dan dua kali berikutnya dengan kontrol gyroscope. Untuk dua kali percobaan dengan kontrol gyroscope konstanta kontroler PID yang diberikan 
berbeda-beda dengan metode tuning secara manual. Dari tabel 3.1, terlihat bahwa kontroler $\mathrm{P}$ memberikan efek yang cukup besar dalam meredam ayunan, yakni $1 \frac{1}{4}$ kali lebih cepat.

\subsubsection{Data Hasil Pengujian Pendulum Secara Keseluruhan}

Berikut ini hasil settling time pengujian pendulum secara keseluruhan tanpa menggunakan gyroscope dan dengan menggunakan gyroscope. Pengujian ini bertujuan untuk melihat berapa lama settling time yang dihasilkan oleh gyroscope dalam meredam ayunan ketika alat dioperasikan.

Table 3.2 Hasil Pengujian pendulum secara keseluruhan

\begin{tabular}{ccccc}
\hline No & $\begin{array}{c}\text { Massa } \\
(\mathbf{k g})\end{array}$ & $\begin{array}{c}\text { Settling Time } \\
\text { Tanpa Gyroscope }\end{array}$ & $\begin{array}{c}\text { Settling Time } \\
\text { Dengan Gyroscope }\end{array}$ & $\begin{array}{c}\text { Nilai Rata-rata } \\
\text { Settling Time }\end{array}$ \\
\hline 1 & $1,0 \mathrm{~kg}$ & $39 \mathrm{~s}$ & $19 \mathrm{~s}$ & $2,05263 \mathrm{~s}$ \\
2 & $1,1 \mathrm{~kg}$ & $49 \mathrm{~s}$ & $22 \mathrm{~s}$ & $2,22727 \mathrm{~s}$ \\
3 & $1,2 \mathrm{~kg}$ & $57 \mathrm{~s}$ & $23 \mathrm{~s}$ & $2,47826 \mathrm{~s}$ \\
4 & $1,3 \mathrm{~kg}$ & $68 \mathrm{~s}$ & $25 \mathrm{~s}$ & $2,72 \mathrm{~s}$ \\
5 & $1,4 \mathrm{~kg}$ & $79 \mathrm{~s}$ & $35 \mathrm{~s}$ & $2,25714 \mathrm{~s}$ \\
6 & $1,5 \mathrm{~kg}$ & $83 \mathrm{~s}$ & $40 \mathrm{~s}$ & $2,075 \mathrm{~s}$ \\
\hline
\end{tabular}

Berdasarkan hasil pengujian pendulum secara keseluruhan, diperoleh settling time yang dihasilkan adalah rata-rata 2,29 kali lebih cepat dibandingkan tanpa kontrol. Untuk overshoot dan rise time tidak banyak berubah, sedangkan steady state error adalah nol. Percobaan ini tidak menggunakan filter karena untuk mendapat waktu respon sebenarnya tanpa efek differensial ataupun integral untuk pengujian tanpa kontrol gyroscope. Oleh karena itu, pada gambar hasil ujicoba terdapat beberapa noise yang muncul.

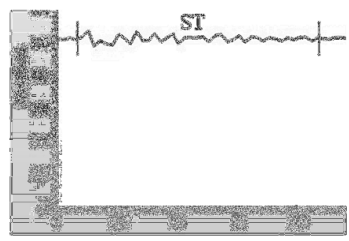

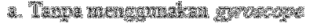

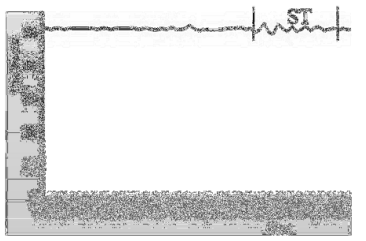

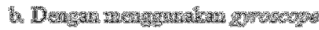
Gambar 3.6 Grafik perbandingan settling time dengan massa $1 \mathrm{~kg}$

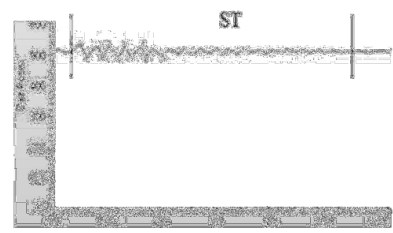

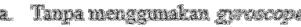

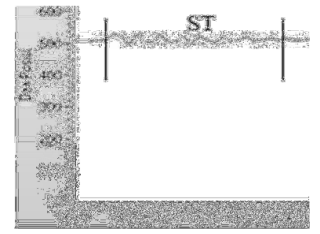

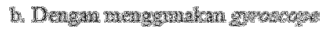

Gambar 3.7 Grafik perbandingan settling time dengan massa 1,1 kg

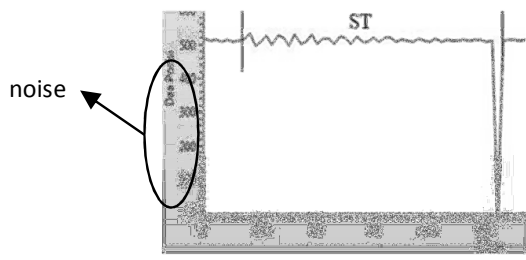

a. Tarypa menggrasakan wrowcover

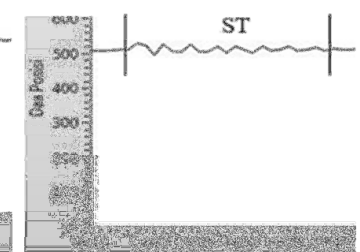

b. Deagan menggusalkan groocope

Gambar 3.8 Grafik perbandingan settling time dengan massa 1,2 kg 


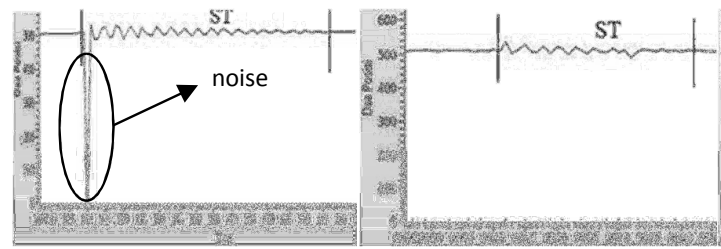

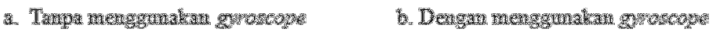

Gambar 3.9 Grafik perbandingan settling time dengan massa 1,3 kg

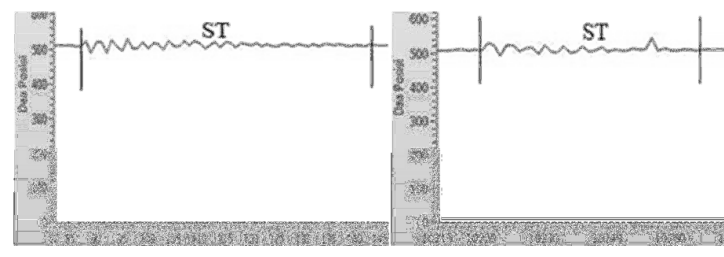

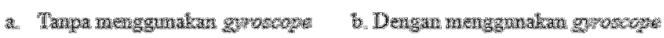

Gambar 3.10 Grafik perbandingan settling time dengan massa $1,4 \mathrm{~kg}$

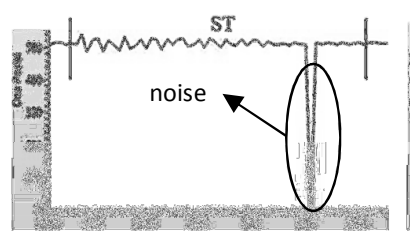

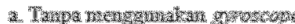

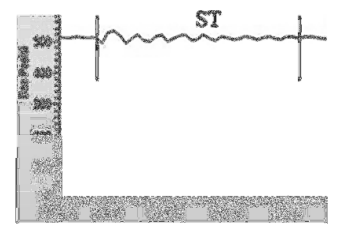

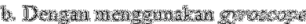

Gambar 3.11 Grafik perbandingan settling time dengan massa 1,5 kg

Dari hasil percobaan diatas dapat diketahui bahwa semakin berat massa yang digunakan maka semakin besar pula gaya yang terjadi pada pendulum dan waktu yang diperlukan semakin lama. Hal ini dikarenakan gaya yang diberikan tehadap suatu benda akan memberikan pengaruh terhadap benda tersebut dan berdasarkan hukum Newton III yaitu jika suatu benda memberikan gaya pada benda lain maka benda yang dikenai gaya akan memberikan gaya yang besarnya sama dengan gaya yang diterima dari benda pertama tetapi arahnya berlawanan.

Sebagai tambahan, setelah menggunakan LPF diperoleh bahwa noise yang ditimbulkan saat pembacaan posisi pendulum oleh sensor dapat dihilangkan.

\section{SIMPULAN}

Berdasarkan hasil pengujian dan analisa dapat ditarik kesimpulan sebagai berikut :

1. Arah respon pendulum berlawanan dengan arah putaran gyroscope. Besarnya respon pendulum tergantung dari kecepatan putaran, massa, dan diameter gyroscope.

2. Settling time yang dihasilkan pada percobaan adalah rata-rata 2,29 kali lebih cepat menggunakan gyroscope dibandingkan tanpa kontrol, sedangkan untuk overshoot dan rise time tidak banyak berubah, serta nilai steady state error adalah nol.

3. Semakin berat massa pada pendulum maka settling time yang dihasilkan semakin lama.

\section{DAFTAR PUSTAKA}

[1]. Wojciech Blajer, Krzysztof Kolodziejczyk, "Motion Planning And Control Of Gantry Cranes In Cluttered Work Environment", IET Control Theory \& Applications, vol. 5, no. 32 pp. 1370-1379, 2007.

[2]. Ryspek Usubamatov, Mathematical Model for Gyroscope's Gimbal Motions [Online], diakses pada 16 Agustus 2017, Available : http://dx.doi.org/10.15242/IIE.E1215033.

[3]. Felix Grasser, Aldo D'Arrigo, Silvio Colombi, Alfred C. Rufer, "JOE: a mobile, inverted pendulum", IEEE Transactions on Industrial Electronics, vol. 49, no. 1, pp. 107-114, 2002. 
[4]. Sunil Kumar Mishra, Dinesh Chandra, Stabilization and Tracking Control of Inverted Pendulum Using Fractional Order PID Controllers [Online], diakses pada 16 Agustus 2017, Available : https://www.hindawi.com/journals/je/2014/752918/.

[5]. Kintan Limiansih, Ign Edi Santosa, "Redaman pada Pendulum Sederhana", Jurusan Pendidikan Fisika, Universitas Sanata Dharma, Yogyakarta, 2013.

[6] Ziyad N. Masoud, Khaled A. Alhazza, "Frequency-Modulation Input Shaping Control of DoublePendulum Overhead Cranes", Journal of Dynamic Systems, Measurement, and Control, vol. 136, no. 2, pp. 53-60, 2103.

[7]. Jordan Meyer, Nathan Delson, Raymond A. de Callafon, "Design, Modeling and Stabilization of A Moment Exchange Based Inverted Pendulum", Journal of Mechanical And Aerospace Engineering, vol. 42, no. 10, pp. 462-467, 2009.

[8]. Mohanarajah Gajamohan, Michael Merz, Igor Thommen, Raffaello D’Andrea, The Cubli: A Cube that can Jump Up and Balance [Online], Diakses pada 15 April 2107, Available : http://citeseerx.ist.psu.edu/.

[9] Dorf. R. C, Bishop R. H. 2008. Modern Control System Eleventh Edition. Pearson International Edition: Prentice Hall. 